\title{
Hierarchies of Motivation Predict Individuals' Attitudes and Values: A Neuropsychological Operationalization of the Five Factor Model
}

\section{Cameron Berg}

\begin{abstract}
Scientific investigations of human personality are concerned with uncovering recurrent patterns of behavior, valuation, and cognition across time. The Five Factor Model (FFM), commonly known as the "Big 5," is considered the most scientifically rigorous consolidation of the components of human decision-making and behavior. This research presents a novel hypothesis for systematizing the factors of the FFM into a series of emotional, motivational, and intellectual trade-offs. 193 adult participants completed an online decision-making battery composed of scenarios generated in accordance with each superordinate trade-off framework. Machine learning algorithms were subsequently implemented to assess whether a participant's individual "score" was able to predict their independently-reported attitudes related to political affiliation, gender identity, career preferences, economic beliefs, political correctness, spirituality, and others. Across every attitude probed, the trade-off framework presented in this research was able to predict participant responses at levels statistically significant at $\mathrm{p}<.00001$. This pilot investigation thus strongly supports the utility of conceptualizing individual decisions, preferences, values, and motivations through the lens of the FFM-based trade-off frameworks outlined in this work.
\end{abstract}




\section{Introduction}

\section{Conceptualizing Personality}

Much like well-being, romantic attraction, and justice, personality is a concept that is both (1) readily employed and understood in popular culture and (2) is unsatisfactorily encapsulated by its simple dictionary definition. In other words, it is universally acknowledged that "personality" refers to something determinate and relevant, but the precise object of its reference remains fairly elusive. Nonetheless, trait-based and behavior-based methods for scientifically investigating human character seem to converge in a scientific understanding of personality as patterns of motivation that an individual displays across time (Corr et al, 2009). Game theoretical and neuroeconomic understandings of human behavior further elucidate this intuition: when presented with identical trade-offs, individuals will regularly diverge in (1) their valuation of the presented options and (2) their subsequent intuitions about the normative action within the tradeoff paradigm (e.g., Platt and Huettel, 2008; Gibbons, 1992). A very straightforward example: Jack might vote for Candidate A while Jill might vote for Candidate B, even though their descriptive knowledge of the political landscape may well be identical. To the extent that these valuation schemas and their implications for behavioral decision-making are non-random, the work of personality neuropsychologists should be thought of as a scientific investigation of the underlying mechanics of an individual's patterns of preference. Of course, humans are nonempirically participating in this quest to anticipate individual behavior and decision-making at varying levels of abstraction: purchasing the right gift one's family member, predicting consumer choices, knowing how to engage with an interlocutor, driving with other vehicles on the road, or socializing during a pandemic all require lay theories of how and why other people make decisions, exhibit preferences, and cultivate tastes - with the explicit stipulation that 
building such models helpfully reduces the staggering complexity of other minds, thereby allowing us to function socially. This everyday capacity to map the intentions, motivations, and behaviors of others is referred to by psychologists as theory of mind (Frith and Frith, 2005); using this vocabulary, one might characterize the (undoubtedly asymptotic) "destination" of personality neuropsychology to be a rigorous, empirical formalization of theory of mind — the everyday intuitions that humans employ to make sense of the decisions of others-especially insofar as these preferences regularly diverge from individual to individual.

\section{Current Models of Personality}

Attempts to model human personality can be traced back to Ancient Greek conceptualizations of the "four temperaments" (Steiner, 1985); notable subsequent inquiry includes Carl Jung's Psychological Types (more commonly known under the Myers-Briggs moniker), Hans Eysenck's Dimensions of Personality, and Jeffrey Alan Gray's related biopsychological theory of personality. Today, however, by far the most dominant and well-respected model of human personality is the Five Factor Model (FFM), also known as the "Big 5." Its eponymous factors are extraversion, neuroticism (or, inversely, emotional stability), conscientiousness, agreeableness, and openness; these five factors are claimed to comprehensively constitute the parameters of human personality. Developed initially by performing straightforward statistical power analyses on verbal descriptors purported to bear relevance to personality (e.g., noticing patterns like that individuals who self-identify as "being a good listener" also tend to selfidentify as "respecting authority"), the FFM is considered dominant in the space of personality models because of its atheoretical derivation (McCrae and Costa, 1987), its general cross-cultural validation (Rammstedt et al, 2012), its ability to predict various attitudes and traits (e.g., 
Paunonen and Ashton, 2001), and — least often noted but still highly relevant — its general harmoniousness with lay intuitions about human character. The FFM is most commonly measured through the Revised NEO Personality Inventory, which asks participants to indicate to what extent they agree with various characterizations (e.g., "keep things tidy," "am the first to act," "formulate ideas clearly") and subsequently reports a population percentile into which the individual falls for each trait (e.g., "25th percentile in the population for neuroticism"). These assessments and their underlying models have proved highly promising in moving personality psychology towards its implicitly-stipulated goal of generating an operationalized theory of human motivation, but in their current form, they are still insufficient. Individual results from these assessments typically correlate with traits like health outcomes, political affiliation, career styles, and learning strategies within the normally distributed range of $r=.1$ to $r=.3$ (e.g., Komarraju et al, 2011; Madnawat and Mehta, 2012; Jokela et al, 2012, Klimstra et al, 2012). While correlations of this magnitude are indeed notable in psychological science, they do not indicate that, in its current form, the FFM comprehensively captures the embodied dynamics of human motivation and real-world behavioral decision-making. Indeed, the FFM should be viewed neither as a hopeless formulation nor as a perfected model of human behavior: instead, this work proposes that FFM can be straightforwardly thought of as the distillation of the necessary components of a rigorous model of motivation. In other words, this research conceptualizes the FFM as an accurate neuropsychological "ingredients list" - but not as a finished recipe in and of itself. 


\section{A Refined Model: Hierarchies of Motivation}

If rigorous theories of personality aim to systematize the various motivational trade-offs across which individuals display patterns in their behavioral decision-making, then the proper reconciliation of the FFM with decision-making trade-off paradigms would move personality psychology closer to a comprehensive model of human motivation. The primary insight that substantiates this assertion is that behavioral decision-making — whose patterns comprise personality - practically occurs within the neural-computational context of selecting one particular behavior from the (environmentally-constrained) larger set of plausible behaviors by computing the risk-reward "profile" for each candidate behavior (Plaus, 1993; Ernst et al, 2004). In other words, if the factors of the FFM were somehow integrated into a set of veridical tradeoff paradigms, this conceptual scaffolding could provide the superordinate structure that transmutes the "ingredients" of the FFM into a neuropsychologically-grounded "recipe" of motivated decision-making.

Instead of assessing participants within traits across individuals, this research investigates across traits within individuals. For instance, instead of asking, "how high in trait $\mathrm{X}$ are you, compared to the greater population?", this research employs the question-framework, "greater population aside, if you are compelled to choose between a behavior associated with trait $\mathrm{X}$ or a behavior associated with trait $Y$, which would you choose?" To the knowledge of the author, this functional application of an ipsative framework to the FFM is novel and has no clear predecessor in the associated literature (with the possible exception of Hirsh and Peterson, 2008). This research operationalizes the FFM into the following six trade-offs: 
Table 1: The Hypothesized FFM Operationalization Trade-Off Paradigms

\begin{tabular}{|c|c|c|c|c|c|}
\hline $\begin{array}{c}\text { Trade-off } \\
\#\end{array}$ & $\begin{array}{l}\text { Psychological } \\
\text { Stratum }\end{array}$ & FFM: Trait One & FFM: Trait Two & Colloquial Trade-Off & $\begin{array}{c}\text { Paradigmatic } \\
\text { Example of Trade- } \\
\text { Off }\end{array}$ \\
\hline 6 & Abstract interest & $\begin{array}{c}\text { Openness to } \\
\text { experience (facet- } \\
\text { level) } \\
\end{array}$ & $\begin{array}{l}\text { Openness to ideas } \\
\text { (facet-level) }\end{array}$ & beauty // truth & $\begin{array}{l}\text { Individual interest in } \\
\text { humanities vs. } \\
\text { sciences. }\end{array}$ \\
\hline 5 & $\begin{array}{l}\text { Goal-Directed } \\
\text { Motivation }\end{array}$ & Openness & Agreeableness & $\begin{array}{l}\text { "psychological" } \\
\text { individualism // } \\
\text { collectivism }\end{array}$ & $\begin{array}{l}\text { A close friend says } \\
\text { something that you } \\
\text { believe is factually or } \\
\text { ethically mistaken. }\end{array}$ \\
\hline 4 & $\begin{array}{l}\text { Goal-Directed } \\
\text { Motivation }\end{array}$ & Openness & Conscientiousness & $\begin{array}{l}\text { "psychological” } \\
\text { liberalism // } \\
\text { conservatism }\end{array}$ & $\begin{array}{l}\text { Maintain what already } \\
\text { works, or attempt to } \\
\text { further refine? }\end{array}$ \\
\hline 3 & $\begin{array}{l}\text { Goal-Directed } \\
\text { Motivation }\end{array}$ & Conscientiousness & Agreeableness & self // other & $\begin{array}{l}\text { Preference for } \\
\text { cooperation vs. } \\
\text { competition. }\end{array}$ \\
\hline 2 & $\begin{array}{c}\text { Positive } \\
\text { Emotionality }\end{array}$ & High extraversion & Low extraversion & energetic // reserved & $\begin{array}{l}\text { How enthusiastic is the } \\
\text { individual upon } \\
\text { receiving good news? }\end{array}$ \\
\hline 1 & $\begin{array}{c}\text { Negative } \\
\text { Emotionality }\end{array}$ & High neuroticism & Low neuroticism & sensitive // resilient & $\begin{array}{l}\text { How upset is the } \\
\text { individual upon } \\
\text { receiving bad news? }\end{array}$ \\
\hline
\end{tabular}

While there is there is a wealth of evidence that all of the trade-offs postulated above are both ubiquitous and tightly correlated to personality (e.g., Kuiper and Rogers, 1979; Amodio et al, 2007; Tsang et al, 2016), their precise configuration represents the author's own conceptualization of their interrelation - the validity of this conceptualization is what this research empirically tests. The grounding hypothesis of this work can thus be outlined: if the stipulated trade-off framework is valid, then when participants respond to a series of forcedchoice scenarios (built in accordance with each trade-off) that each compels the prioritization of behavior associated with one of the two traits, they will (1) display regularities in decisionmaking across different scenarios that employ the same trade-off, and (2) these regularities, across scenarios, will demonstrate the participant's hierarchy of motivations, or equivalently, 
their hierarchy of values (Peterson, 1999). In other words, if the FFM and the associated tradeoff framework are both legitimate, then an assessment built in accordance with this trade-off framework would comprehensively operationalize the major behavioral decision-making dilemmas encountered in a life lived with a human nervous system, and, by the conclusion of the assessment, retroactively elucidate the intrapersonal motivational preferences of the particular participant (without the need for referencing to any wider population data).

\section{Methods}

\section{Structure of Assessment}

Based on the trade-off framework from the previous section, a full-scale, online personality assessment was designed using Python, HTML, CSS, and JavaScript. The assessment was composed of 42 scenarios: each of the two emotionality trade-offs featured in 5 scenarios, while the remaining four trade-offs featured in 8 scenarios each. Prior to this research, earlier forms of the assessment had been twice administered in pilot trials, and its scenarios had thus been twice revised in an attempt to maximize their internal consistency within each trade-off paradigm (with reference to Cronbach's alpha). Scenarios were randomly shuffled for each participant to minimize inadvertent ordering biases. Within each scenario, participants were presented with a simple dilemma, followed by two plausible responses to the dilemma that corresponded to behaviors associated with each trait in the trade-off being tested. The task of each participant was simply to descriptively predict their most likely response using an interactive slider, ranging

from "Extremely confident that I would select Response 1" to "Extremely confident that I would select Response 2”. 
Your family member brings up an interesting but controversial topic at the dinner table.

\section{Predict your response:}

Response 1: Steer the conversation away from controversy.

Response 2: Pursue the interesting topic.

0

Not sure what I would do.

\section{1}

Extremely confident that I would select Response 2.

\section{6}

Confident that I would select Response 1.

Figure 1: Sample scenario, probing trade-off 2; interactive slider values

Algorithmically, each scenario decision allots a quantity of points to the "winning" motivation that varies directly with the magnitude of the participant's preference for the choice associated with that motivation; by the conclusion of the assessment, each trait referenced in one or more trade-offs was assigned its associated numerical value, which allowed for the subsequent calculation of the participant's hierarchies of motivations (with one hierarchy per psychological stratum, as outlined in Table 1). 


\section{Participants}

193 American adults participated in this more formalized pilot trial $(f=137)$. Participants responded to a simple online advertisement for the assessment, and, in return for their participation, were presented with a customized explanation of their results at the conclusion of the assessment. Prior to beginning the assessment, participants provided standard informed consent to participate. Multiple participants did not fully complete the assessment, and their data was removed from the dataset prior to conducting any statistical analyses.

\section{Attitudes and Opinions}

At the conclusion of assessment (and before viewing results), participants were asked to confidentially and optionally share a series of personal opinions, beliefs, and attitudes using slider scales similar to those encountered during the scenarios. Participants were explicitly informed that their responses in this section would have no bearing on the assessment result.

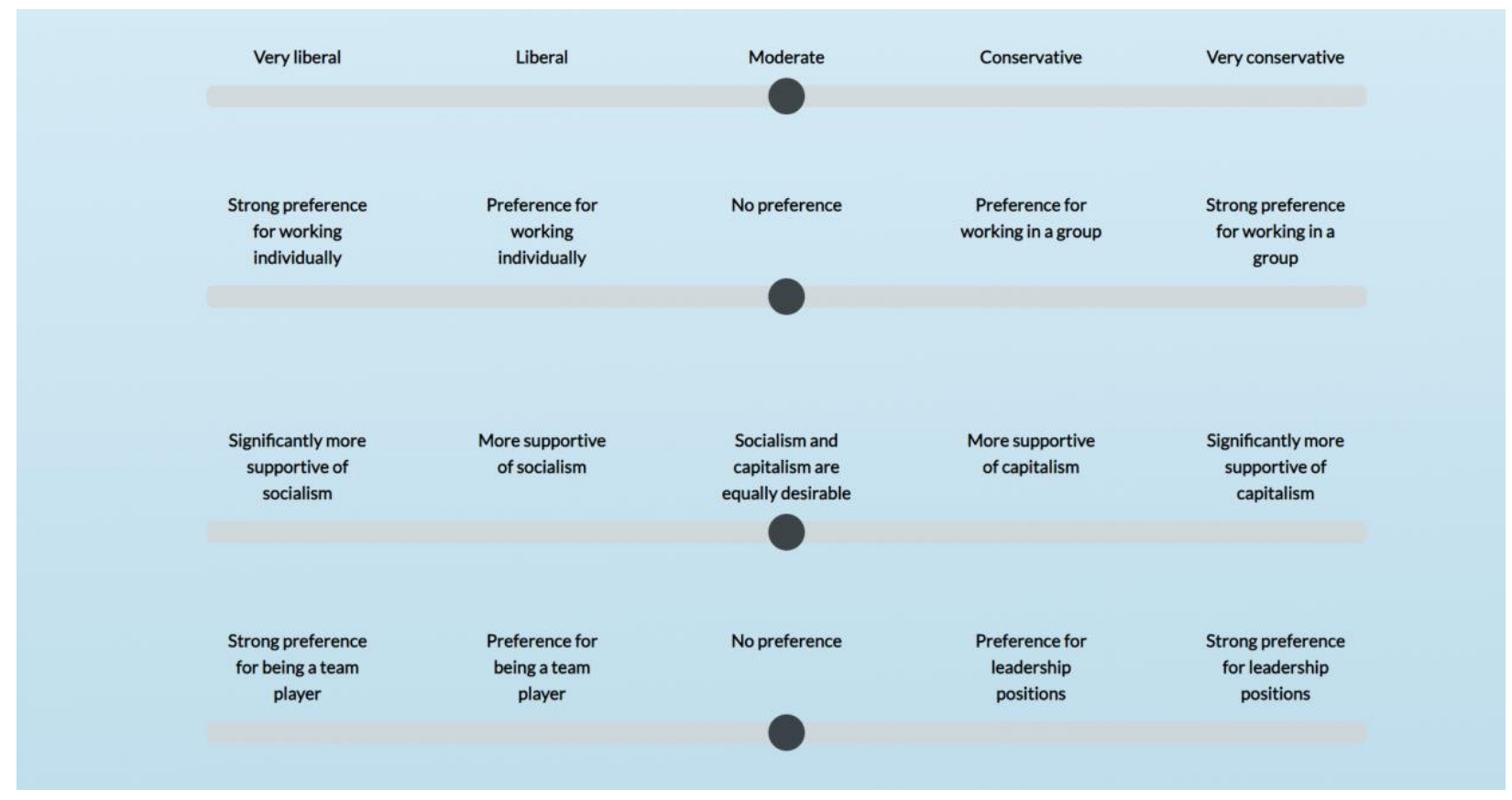

Figure 2: Sample slider scales for attitudes and opinions section of the pilot study. 
In total, participants were asked to respond to 12 slider-scale items that resemble those shown in Figure 2 and two binary options (biological sex; straight-identifying or not-straight-identifying).

Only the participants who chose to complete this section in its entirety were included in the dataset related to external predictability.

\section{Results}

\section{Internal Consistency}

Participant results were first analyzed to assess the validity of individual decision-making scenarios in relationship to their superordinate trade-off category. The Cronbach's alpha coefficient for each trade-off paradigm is summarized in Table 2.

Table 2: Cronbach's Alpha by Trade-Off Paradigm

\begin{tabular}{|c|c|c|c|c|c|}
\hline $\begin{array}{c}\text { Trade-off } \\
\#\end{array}$ & $\begin{array}{c}\text { Psychological } \\
\text { Stratum }\end{array}$ & FFM: Trait One & FFM: Trait Two & Colloquial Trade-Off & Cronbach's $\boldsymbol{\alpha}$ \\
\hline $\mathbf{1}$ & Abstract interest & $\begin{array}{c}\text { Openness to } \\
\text { experience (facet- } \\
\text { level) }\end{array}$ & $\begin{array}{c}\text { Openness to ideas } \\
\text { (facet-level) }\end{array}$ & beauty // truth & .82 \\
\hline $\mathbf{2}$ & $\begin{array}{c}\text { Goal-Directed } \\
\text { Motivation }\end{array}$ & Openness & Agreeableness & $\begin{array}{c}\text { "psychological" } \\
\text { individualism // } \\
\text { collectivism }\end{array}$ & .63 \\
\hline $\mathbf{3}$ & $\begin{array}{c}\text { Goal-Directed } \\
\text { Motivation } \\
\text { liberalism // } \\
\text { conservatism }\end{array}$ & Openness & Conscientiousness & .69 \\
\hline $\mathbf{4}$ & $\begin{array}{c}\text { Goal-Directed } \\
\text { Motivation }\end{array}$ & Conscientiousness & Agreeableness & self //her & .66 \\
\hline $\mathbf{5}$ & $\begin{array}{c}\text { Positive } \\
\text { Emotionality }\end{array}$ & High extraversion & Low extraversion & energetic // reserved & .56 \\
\hline
\end{tabular}




\section{Intercorrelation Matrix}

The empirical question of this research resides in whether individuals' hierarchies of motivation are predictive. In other words, do assessment results—and by close extension, the FFM trade-off framework upon which the assessment is grounded - display correlations to the everyday, real opinions, attitudes, and beliefs of participants? The first and most basic investigation of this research question involves the analysis of Pearson correlation coefficients between assessment results and self-reported attitudes, opinions, and beliefs, represented in Table 3.

Table 3: Intercorrelation matrix between ipsative trade-off framework features and self-reported attitudes, opinions, and beliefs.

\begin{tabular}{|c|c|c|c|c|c|c|c|c|c|c|c|c|c|}
\hline & & \multicolumn{12}{|c|}{ Intercorrelation Matrix: Model Features and Predicted Variables } \\
\hline & & \multicolumn{12}{|c|}{ Ipsative Model Features: } \\
\hline & & openness & conscientiousness & agreeableness & extraversion & neuroticism & $\begin{array}{c}\text { openness } \\
\text { to ideas }\end{array}$ & $\begin{array}{l}\text { openness to } \\
\text { experience }\end{array}$ & $\mathrm{c} / \mathrm{a}$ & $0 / c$ & $a / 0$ & $e / n$ & o.i./o.e. \\
\hline \multirow{14}{*}{ 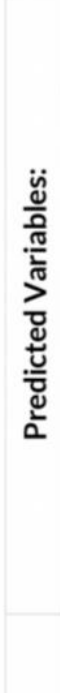 } & age & -0.077 & -0.196 & $\underline{0.275}$ & -0.135 & -0.231 & -0.167 & 0.167 & -0.196 & 0.021 & 0.206 & 0.084 & -0.158 \\
\hline & gender ( $M$ or $F$ ?) & 0.065 & 0.180 & $\underline{-0.247}$ & 0.213 & -0.072 & 0.143 & -0.143 & 0.234 & 0.006 & -0.183 & 0.171 & 0.174 \\
\hline & sexuality (straight or not?) & -0.129 & 0.171 & -0.054 & 0.061 & -0.123 & 0.075 & -0.075 & 0.113 & -0.211 & 0.062 & 0.099 & 0.065 \\
\hline & masculine-feminine & -0.156 & -0.164 & $\underline{0.317}$ & -0.130 & 0.038 & $\underline{-0.254}$ & $\underline{0.254}$ & -0.231 & -0.096 & $\underline{0.288}$ & -0.106 & -0.230 \\
\hline & liberal-conservative & -0.151 & $\underline{0.265}$ & -0.130 & 0.045 & -0.018 & 0.159 & -0.159 & $\underline{0.239}$ & -0.211 & 0.021 & 0.041 & 0.201 \\
\hline & solitary-groupwork & -0.153 & -0.007 & 0.153 & $\underline{0.281}$ & -0.130 & -0.123 & 0.123 & 0.001 & 0.011 & 0.142 & $\underline{0.298}$ & -0.130 \\
\hline & socialism-capitalism & -0.092 & $\underline{0.304}$ & -0.226 & 0.134 & -0.022 & 0.270 & -0.270 & $\underline{0.280}$ & -0.204 & -0.090 & 0.096 & 0.257 \\
\hline & "teamplayer"-leader & 0.043 & $\underline{0.358}$ & -0.411 & 0.275 & 0.096 & 0.226 & -0.226 & $\underline{0.388}$ & -0.141 & -0.255 & 0.031 & 0.226 \\
\hline & nonspiritual-spiritual & -0.036 & -0.216 & $\underline{0.257}$ & -0.165 & -0.038 & -0.274 & 0.274 & -0.228 & 0.128 & 0.153 & -0.013 & $\underline{-0.250}$ \\
\hline & honest-dishonest & 0.074 & 0.142 & -0.217 & 0.047 & 0.025 & 0.158 & -0.158 & $\underline{0.308}$ & -0.045 & -0.175 & -0.044 & 0.082 \\
\hline & nondedicated-dedicated & 0.076 & 0.059 & -0.133 & $\underline{0.324}$ & 0.061 & 0.013 & -0.013 & 0.101 & 0.091 & -0.101 & 0.198 & 0.095 \\
\hline & politically_correct-notPC & -0.026 & $\underline{-0.244}$ & $\underline{0.277}$ & -0.162 & 0.042 & -0.170 & 0.170 & -0.220 & 0.059 & 0.173 & -0.099 & -0.138 \\
\hline & inarticulate-articulate & 0.179 & 0.006 & -0.177 & 0.154 & -0.048 & 0.069 & -0.069 & 0.212 & 0.088 & -0.202 & 0.139 & 0.123 \\
\hline & & $\begin{array}{l}(n=193) \\
\text { value }=p\end{array}$ & value $=p<.0$ & 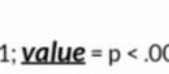 & & & & & & & & & \\
\hline
\end{tabular}

\section{Machine Learning Models}

In additional to the analyzing the Pearson correlation coefficients displayed in Table 3, new machine learning programming techniques were employed to further assess the extent to which the numerical output of the assessment predicts user opinions, beliefs, and attitudes. Using 
models from the sci-kit learn library and the AutoML genetic programming tool, TPOT, a series of classification and regression experiments were performed. Where a column is labeled "split down average," this indicates that linear values were converted to a " 0 " or " 1 " depending on whether they fell above or below the 50th percentile in the dataset. Where a column is labeled "pole differentiation," this indicates that linear values were converted to a " 0 " or " 1 " depending on whether they fell above or below the 85th percentile in the dataset; all other data was temporarily omitted. All generated linear regression models were significant at $p<.00001$. These correlations are the product of a five-fold cross validation on a hold-out sample (to avoid overfitting). All generated models have been uploaded to https://github.com/camberg23/personality_project. 
Table 4: Data from machine learning regression and classification experiments for each attitude, opinion, and belief surveyed.

\begin{tabular}{|c|c|c|c|c|}
\hline predicted variable & $\mathbf{r}$ & $\begin{array}{l}\text { significant at } \\
\mathrm{p}<.00001 ?\end{array}$ & $\begin{array}{c}\text { binary } \\
\text { classification } \\
\text { (split down } \\
\text { average) }\end{array}$ & $\begin{array}{l}\text { binary classification } \\
\text { (pole differentiation) }\end{array}$ \\
\hline biological sex (M/F) & -- & -- & .775 & -- \\
\hline $\begin{array}{r}\text { identifies as straight } \\
(\mathrm{Y} / \mathrm{N}) \\
\end{array}$ & -- & -- & .750 & -- \\
\hline $\begin{array}{r}\text { articulates thoughts } \\
\text { well }\end{array}$ & .467 & Yes & .724 & .826 \\
\hline $\begin{array}{r}\text { supports capitalism (vs. } \\
\text { socialism) }\end{array}$ & .399 & Yes & .734 & .735 \\
\hline $\begin{array}{r}\text { supports conservatism } \\
\text { (vs. liberalism) }\end{array}$ & .407 & Yes & .715 & .777 \\
\hline $\begin{array}{r}\text { identifies as feminine } \\
\text { (vs. masculine) } \\
\end{array}$ & .517 & Yes & .683 & .785 \\
\hline $\begin{array}{r}\text { identifies as dedicated } \\
\text { to work } \\
\end{array}$ & .443 & Yes & .744 & .803 \\
\hline $\begin{array}{r}\text { identifies as leader (vs. } \\
\text { "team player") }\end{array}$ & .567 & Yes & .746 & .795 \\
\hline lies often & .399 & Yes & .688 & .767 \\
\hline $\begin{array}{r}\text { identifies as politically } \\
\text { correct }\end{array}$ & .450 & Yes & .685 & .775 \\
\hline identifies as spiritual & .345 & Yes & .743 & .793 \\
\hline $\begin{array}{r}\text { prefers teamwork (to } \\
\text { individual work) }\end{array}$ & .381 & Yes & .704 & .813 \\
\hline
\end{tabular}




\section{Discussion}

The results of this research strongly support the hypothesized trade-off framework posited in Table 1. Using a simple decision-making battery programmed in accordance with the trade-off framework, traits as diverse as political affiliation, communication skills, gender identity, spirituality, and social preferences - traits that serve as real-world manifestations of personality differences across individuals — were all predicted at levels statistically significant at p-values less than .00001. To the knowledge of the author, the machine-learning-generated linear regressions between the features of the FFM trade-off framework and self-reported attitudes and beliefs are state-of-the-art; despite performing a fairly exhaustive literature review, no existing research could be found that claimed to uncover correlations between personality and political, social, professional, academic, and personal attitudes that approach the magnitude of those described in the linear regression experiments in Table 4 (e.g., Rosenfeld, 2018; Forrester and Tashchian, 2010; Chirumbolo and Leone, 2010; Lowicki, 2019; Erceg et al, 2018; Birkeland and Buch, 2015; Sutin et al, 2012; Moss and O'Connor, 2020). By simply inputting a numerical representation of an individual's hierarchy of motivations into the machine learning models generated by this research, the correct half of each of the attitudinal spectra upon which the individual self-identified (e.g., more liberal, or more conservative?) could be predicted $72.4 \%$ of the time, on average. If the individual strongly self-identified with one end of a spectrum (e.g., identified as strongly liberal), their hierarchy of motivations predicted this $78.7 \%$ of the time, on average. And in terms of precisely localizing an individual on each spectrum, the machine learning linear regression models demonstrated an average correlation coefficient (across all surveyed attitudes) of $r=.44$, with a maximum at $r=.57$ (self-reported leadership) and a minimum at $\mathrm{r}=.35$ (self-reported spirituality). 
The Pearson correlation coefficients displayed in Table 3 helpfully demonstrate the particular motivations whose differential selection helped to predict the various surveyed attitudes. For example, participants' final ratios of conscientiousness to agreeableness correlated at $r=.388(p$ $<.00001)$ with their individual self-reported preferences for leadership roles, participants' final extraversion scores correlated at $\mathrm{r}=.324(\mathrm{p}<.00001)$ with their individual self-reported levels of “dedication to their work," and participants' final openness to experience scores correlated at $r=$ $.274(\mathrm{p}<.001)$ with their individual self-reported spirituality.

Internal consistency of individual scenarios within trade-off paradigms was generally adequate, but ultimately mixed. While $\alpha=.82$ for trade-off one in Table 1 (openness to ideas vs. openness to experience), a relatively strong indicator of the internal validity of this particular paradigm, the remaining five paradigms displayed $\alpha$ values ranging from .53 to .69 , demonstrating acceptable but mediocre internal consistency. While the inherent generality of trade-off paradigms assessed in this research may allow for lower $\alpha$ values than may be traditionally accepted, a major area for future research into the model proposed in this work includes the continued refinement and scale-level validation of the individual decision-making scenarios designed in accordance with each trade-off. That such statistically powerful linear regression models and correlation coefficients were able to be extracted from final participant assessment results seems to vindicate the relevance and cogency of the fundamental assumptions of the tested trade-off framework, in spite of the fact that more research is clearly required to further fine-tune its implementation. 


\section{Conclusions}

The scientific investigation of human character has progressed immeasurably since Hippocrates' delineation of the "four temperaments;" in the place of individual guesswork, the FFM has emerged as the definitive comprehensive account of persistent differences in human motivation and, on account of its durable mathematical underpinnings, has remained dominant to this day. But its further refinement has also proved largely stagnant over the past two decades. Assessments built in accordance with the "Big 5" model (as it has been colloquially dubbed) are useful for assessing how high or low an individual is in some trait (e.g., agreeableness) in relation to the greater population, these assessments do very little to elucidate the intrapersonal dynamics that arise between traits for every individual, despite the fact that such dynamics (1) obviously exist as a matter of subjective experience and (2) are what constitute and calibrate individual decision-making, and ultimately, behavior. By transmuting the "ingredients" of the FFM into a coherent hierarchy of trade-off paradigms that encompass emotionality, goal-directed motivation, and abstract interest, the unique internal dynamics of an individual's behavioral decision-making process can be elucidated with unprecedented clarity and transparency, without need for referencing any wider population data. In addition to generating powerful empirical predictions of a wide range of attitudes, beliefs, and opinions, this model also seems to conserve our basic intuitions about human behavior: it implicitly postulates that all "psychologically normal" people value the same things (e.g., being productive, being prosocial, being interested) but that individuals significantly differ in how they prioritize these things (e.g., Jim might generally care more about being prosocial than being productive, while Jason might generally care more about being productive than being prosocial, but both still care a lot about both productivity and prosociality.) In this way, the proposed model of human motivation allows us to 
have our proverbial cake and eat it, too, in the simultaneous, noncontradictory recognition that humans are both (1) exceptionally similar to one another (we all generally value the same things), and (2) exceptionally different to one another (we all generally do not value these things in the same order). Elucidating the similarities and differences between human minds in this way carries significant political, philosophical, and sociocultural weight—such insights are a necessary precondition for successfully navigating the highly complex, frustratingly perennial, and increasingly prominent phenomena of radicalism, racism, polarization, and the othering of those whose values diverge from our own.

While the scope of the trade-off framework proposed in this work is ambitious, it is critical to explicitly outline its limitations. First, the machine learning linear regression models yielded from this research can be holistically summarized as predicting (binarized) self-reported participant attitudes, beliefs, and opinions with roughly $75 \%$ accuracy: this allows for the characterization of the hypothesized motivational framework as halfway between a random guess (50\%) and a deterministic model of human motivation (100\%). Of course, any model of human decision-making cannot account for the various circumstantial, sociocultural, and environmental factors that self-evidently modulate an individual's real-world perspectives — it is likely here, in the "minutiae of external circumstances," where much of the remaining variance lurks. Relatedly, a deterministic theory of human behavior - a perfect predictive model of individual decision-making - appears to be both conceptually impossible (for all of the Gleickian reasons why any chaotic, self-entangled system is technically unpredictable) and normatively undesirable. While the human mind can be validly construed as a puzzle to be solved—and highly useful insights can and do emerge from this mode of construal - it is prudent to note that 
exclusively (or disproportionately) viewing oneself or others through this empirical, investigatory lens runs the risk of conflating a human being with a motivated machine, and in so doing, threatens to subordinate the beauty of our mental lives to mere models of the processes that govern them. Better understandings the mechanics of human motivation are neither inherently good nor bad: they are complicated, and their ethical valence is constituted in their applications, not in their existence alone. The idealist will understand such advances in the context of enhanced self-understanding, refined recruitment techniques, the amelioration of bitter partisan divides, and the sophistication of our understandings of others' wants and needs. The cynic, meanwhile, might lament advertisers' newfound footholds into our minds, the psychological customization of political propaganda, the advent of powerful new tactics for manipulation, and the reductionist collapse of human decision-making into a series of numbers. As such research inevitably continues, both perspectives are not only valid, but mutually necessary.

The most obvious and necessary direction for future research in accordance with the model presented in this work is localizing its neurofunctional and neuroanatomical correlates. While substantial evidence already supports the view that cognition related to self and other, positive and negative emotion, and abstract interest are valid frameworks through which to understand and interpret major circuitry of the human brain, evidence that a participant's neurological activity can be correlated to or predictive of an their motivational hierarchy would further support the trade-off framework posited in this research (Decety and Sommerville, 2003; Ahern and Schwartz, 1985; Binder et al, 2006). Additionally, successfully reconciling the increasingly extensive literature on hierarchical neurological systems involved in goal pursuit (e.g., Spielberg 
et al, 2013) and the specific classes of motivational hierarchies proposed in this work would significantly enrich the scope and conceptual clarity of both domains. Outside of cognitive science, an elucidated conceptualization of human motivation bears substantial relevance to the diverse inquiries of political science, moral philosophy, sociology, law, the humanities, behavioral economics, and consumer marketing.

\section{Acknowledgements}

In the operationalization, programming, analysis, and reporting of this research, the author is very grateful for the assistance offered by the student researchers Gia Gambino, Yazan Alrayyes, Mishaal Kandapath, Patrick Li, Keshav Ramesh, Niloufar Davis, Dominik Dimitrov, Lina Olfi, Coralys Romero, Dominic Yankiv, Samiyra Afife, Joey Chen, Katie Roberts, Yasti Ranjith, Umid Usmanov, Jomills Anand, Viktoria Wulff-Andersen, Owen Patrick, Maria Grabowsky, Sofia Trecenti, Frank Chiu, Pavla Petrova, Ryan Suh, Christian Bernard, Dylan Cawley, Hamza Shili, Suhanee Giroti, Brittany Peng, Roux-Che Kahireke, and Yunqing Han. 


\section{References}

Ahern, G. L., \& Schwartz, G. E. (1985). Differential lateralization for positive and negative emotion in the human brain: EEG spectral analysis. Neuropsychologia, 23(6), 745-755. https://doi.org/10.1016/0028-3932(85)90081-8

Binder, J. R., Westbury, C. F., McKiernan, K. A., Possing, E. T., \& Medler, D. A. (2005). Distinct Brain Systems for Processing Concrete and Abstract Concepts. Journal of Cognitive Neuroscience, 17(6), 905-917. https://doi.org/10.1162/0898929054021102

Birkeland, I., \& Buch, R. (2015). The Dualistic Model of Passion for Work: Discriminate and Predictive Validity with Work Engagement and Workaholism. Motivation and Emotion, 39. https://doi.org/10.1007/s11031-014-9462-x

Chirumbolo, A., \& Leone, L. (2010). Personality and politics: The role of the HEXACO model of personality in predicting ideology and voting. Personality and Individual Differences, 49(1), 43-48. https://doi.org/10.1016/j.paid.2010.03.004

Corr, P., \& Matthews, G. (2009). The Cambridge Handbook of Personality Psychology. 1-906. https://doi.org/10.1017/CBO9780511596544.002

Decety, J., \& Sommerville, J. A. (2003). Shared representations between self and other: A social cognitive neuroscience view. Trends in Cognitive Sciences, 7(12), 527-533. https://doi.org/10.1016/j.tics.2003.10.004

Erceg, N., Galic, Z., \& Bubić, A. (2018). The Psychology of Economic Attitudes - Moral Foundations Predict Economic Attitudes beyond Socio-Demographic Variables. Croatian Economic Survey, 20, 37-70. https://doi.org/10.15179/ces.20.1.2

Ernst, M., Nelson, E. E., McClure, E. B., Monk, C. S., Munson, S., Eshel, N., Zarahn, E., Leibenluft, E., Zametkin, A., Towbin, K., Blair, J., Charney, D., \& Pine, D. S. (2004). 
Choice selection and reward anticipation: An fMRI study. Neuropsychologia, 42(12), 15851597. https://doi.org/10.1016/j.neuropsychologia.2004.05.011

Forrester, W. R., \& Tashchian, A. (2010). Effects Of Personality On Attitudes Toward Academic Group Work. American Journal of Business Education (AJBE), 3(3), 39-46. https://doi.org/10.19030/ajbe.v3i3.397

Frith, Chris, and Uta Frith. "Theory of mind." Current biology : CB vol. 15,17 (2005): R644-6. doi:10.1016/j.cub.2005.08.041

Gibbons, R. (1992). A primer in game theory. Undefined. /paper/A-primer-in-game-theoryGibbons/aa54ff493429db9b6298a6e40a8d7b3adb2737c9

Hirsh, J. B., \& Peterson, J. B. (2008). Predicting creativity and academic success with a "FakeProof" measure of the Big Five. Journal of Research in Personality, 42(5), 1323-1333. https://doi.org/10.1016/j.jrp.2008.04.006

Jokela, M., Hintsanen, M., Hakulinen, C., Batty, G. D., Nabi, H., Singh-Manoux, A., \& Kivimäki, M. (2013). Association of personality with the development and persistence of obesity: A meta-analysis based on individual-participant data. Obesity Reviews, 14(4), 315323. https://doi.org/10.1111/obr.12007

Klimstra et al. - 2012 - Personality Traits and Educational Identity Format.pdf. (n.d.). Retrieved December 21, 2020, from https://pure.uvt.nl/ws/portalfiles/portal/1461188/OntwikPsy_Klimstra_personality_JoYaA 2012.pdf

Klimstra, T. A., Luyckx, K., Germeijs, V., Meeus, W. H. J., \& Goossens, L. (2012). Personality Traits and Educational Identity Formation in Late Adolescents: Longitudinal Associations 
and Academic Progress. Journal of Youth and Adolescence, 41(3), 346-361.

\section{https://doi.org/10.1007/s10964-011-9734-7}

Komarraju, M., Karau, S. J., Schmeck, R. R., \& Avdic, A. (2011). The Big Five personality traits, learning styles, and academic achievement. Personality and Individual Differences, 51(4), 472-477. https://doi.org/10.1016/j.paid.2011.04.019

Kuiper, N. A., \& Rogers, T. B. (1979). Encoding of personal information: Self-other differences. Journal of Personality and Social Psychology, 37(4), 499-514. https://doi.org/10.1037/0022-3514.37.4.499

Łowicki, P., \& Zajenkowski, M. (2020). Empathy and Exposure to Credible Religious Acts during Childhood Independently Predict Religiosity. The International Journal for the Psychology of Religion, 30(2), 128-141. https://doi.org/10.1080/10508619.2019.1672486

Madnawat, A. V. S., \& Mehta, P. (2012). Personality as a predictor of burnout among managers of manufacturing industries. Journal of the Indian Academy of Applied Psychology, 38(2), $321-328$.

McCrae, R. R., \& Costa, P. T. (1987). Validation of the five-factor model of personality across instruments and observers. Journal of Personality and Social Psychology, 52(1), 81-90. https://doi.org/10.1037/0022-3514.52.1.81

Moss, J. T., \& O’Connor, P. J. (2020). Political correctness and the alt-right: The development of extreme political attitudes. PLOS ONE, 15(10), e0239259.

$$
\text { https://doi.org/10.1371/journal.pone.0239259 }
$$

Neurocognitive correlates of liberalism and conservatism | Nature Neuroscience. (n.d.).

Retrieved December 21, 2020, from https://www.nature.com/articles/nn1979 
Paunonen, S. V., \& Ashton, M. C. (2001). Big Five factors and facets and the prediction of behavior. Journal of Personality and Social Psychology, 81(3), 524-539. https://doi.org/10.1037/0022-3514.81.3.524

Peterson, J. B. (1999). Maps of Meaning: The Architecture of Belief. Psychology Press.

Platt, M. L., \& Huettel, S. A. (2008). Risky business: The neuroeconomics of decision making under uncertainty. Nature Neuroscience, 11(4), 398-403. https://doi.org/10.1038/nn2062

Plous, S. (1993). The psychology of judgment and decision making (pp. xvi, 302). Mcgraw-Hill Book Company.

Rammstedt, B., Kemper, C. J., \& Borg, I. (2013). Correcting Big Five Personality Measurements for Acquiescence: An 18-Country Cross-Cultural Study. European Journal of Personality, 27(1), 71-81. https://doi.org/10.1002/per.1894

Rosenfeld, J. (2018). Detecting Concealed Information and Deception. Elsevier. https://doi.org/10.1016/C2016-0-03911-6

S0960-9822(05)00960-7.pdf. (n.d.). Retrieved December 21, 2020, from https://www.cell.com/current-biology/pdf/S0960-9822(05)00960-7.pdf

Spielberg, J. M., Heller, W., \& Miller, G. A. (2013). Hierarchical Brain Networks Active in Approach and Avoidance Goal Pursuit. Frontiers in Human Neuroscience, 7. https://doi.org/10.3389/fnhum.2013.00284

Steiner, R. (1985). The Four Temperaments. SteinerBooks.

Sutin, A. R., Terracciano, A., Kitner-Triolo, M. H., Uda, M., Schlessinger, D., \& Zonderman, A. B. (2011). Personality Traits Prospectively Predict Verbal Fluency in a Lifespan Sample. Psychology and Aging, 26(4), 994-999. https://doi.org/10.1037/a0024276 
Tsang, T. L. (2019). A quantitative analysis examining differences between US humanities and STEM students' propensity toward innovation. Journal of Further and Higher Education, 43(2), 149-165. https://doi.org/10.1080/0309877X.2017.1357069 